\title{
ACE Gene I/D polymorphism and systemic arterial hypertension in different classes of hypertensive individuals
}

\begin{abstract}
Systemic arterial hypertension (SAH) is a multifactorial clinical condition characterized by high and sustained levels of blood pressure (BP). Some studies have reported that variants of the angiotensin-converting enzyme (ace) gene increase the risk of hypertension. The aim of this study was to verify the existence of the relationship between the insertion/deletion (I/D) polymorphism in the $\mathrm{ACE}$ gene and its genotypic variants with BP in four distinct groups of hypertensive individuals and also to genetically and epidemiologically characterize the investigated samples. The study was formed of 112 individuals arranged into the following groups: normotensive (control); hypertensive and non-obese; hypertensive and obese; and, hypertensive and with type 2 diabetes mellitus (T2DM). Epidemiological data and peripheral blood were collected from participants for DNA extraction and amplification by PCR (polymerase chain reaction). The allele $(\mathrm{D}=0.5446 ; \mathrm{I}=0.4554)$ and genotype (DD $=0.2411$, ID $=0.6071$; II $=0.1518)$ frequencies showed low genetic differentiation $($ Fst $<0.05)$ and were outside the Hardy-Weinberg equilibrium $(\mathrm{p}<0.05)$. There was no significant difference between the groups (chi-square $=4.4335 ; \mathrm{p}=0.6174$ ). There was no association of the $\mathrm{D}$ allele with $\mathrm{SAH}$, reinforcing the hypothesis that environmental interferences are prevalent in the evolution of SAH.
\end{abstract}

Keywords: ACE, SAH, Obesity, type 2 Diabetes mellitus
Volume 4 Issue I - 2019

\author{
Rubia Caldas Umburanas,' Priscila Costa \\ Estabile,' Rogério Pincela Mateus, ${ }^{2}$ Mara \\ Cristina de Almeida,' Roberto Ferreira \\ Artoni \\ 'Department of Structural Molecular and Genetic Biology, Ponta \\ Grossa State University, Brazil \\ 2Department of Biological Sciences, Postgraduate Program in \\ Evolutionary Biology, State University of Central-West, Brazil
}

\begin{abstract}
Correspondence: Roberto Ferreira Artoni, Department of Structural, Molecular and Genetic Biology, Graduate Program in Evolutionary Biology, State University of Ponta Grossa. Av. Carlos Cavalcanti, 4748, CEP 84030-900, Ponta Grossa, Paraná, Brazil, Email rfartoni@gmail.com
\end{abstract}

Received: December 14, 2018 | Published: February 19, 2019

\section{Introduction}

Systemic arterial hypertension (SAH) is a multifactorial clinical condition characterized by high and sustained levels of blood pressure (BP). ${ }^{1}$ Over the past 30 years there has been a large increase in the prevalence of illness and deaths due to chronic diseases such as cardiovascular diseases and diabetes mellitus ${ }^{1 a}$ with SAH playing an important part in this trend.

The number of hypertensive patients in Brazil has increased considerably this is due to lifestyle, with high salt intake and a sedentary lifestyle, among other factors. Moreover, according to Young, ${ }^{2}$ the epidemiological spread of SAH is due, in part, to the evolutionary history of humans in relation to adaptation to climate, first in Africa and later in the rest of the world. The same study suggests that populations originating from cold regions have more susceptibility to hypertension than those who live in hot and humid environments, due to the fact that salt and water retention is more common in cold climates. ${ }^{2}$

The renin-angiotensin-aldosterone system (RAAS) plays an important role in controlling BP. ${ }^{3}$ Many gene components of this system have been studied because of their role in the regulation of $\mathrm{BP}^{4}$ The angiotensin-converting enzyme (ACE) is a key component of the RAAS in the regulation of BP. ${ }^{5}$ This enzyme plays an important role in the production of angiotensin II and the catabolism of bradykinin; the latter is involved in the modulation of vascular tone and the proliferation of smooth vascular muscle cells. ${ }^{6}$

It has been suggested that the Ace gene may have its activity genetically regulated by the polymorphism of insertion/deletion (I/D) of an ALU sequence of $278 \mathrm{bp}$, in the intron 16, ${ }^{7}$ close to the ${ }^{1 a}$ Ministério da Saúde. DATASUS. SISHiperdia. Presentation. National Coordination of HA and DM. Department of Basic Attention. Department of Health Care.
3' extremity of the intron. ${ }^{8}$ This I/D polymorphic variation produce three possible genotypes: II, ID and DD. ${ }^{8}$ Individuals with the DD genotype have increased plasma levels of ACE, as compared with the genotype II, suggesting that the I/D polymorphism regulates the circulating quantity of the enzyme.${ }^{6}$ Currently, there are two schools of thought about the physiological role of this polymorphism concerning the control of BP. One hypothesis is that the physiological changes in the circulating quantity of the enzyme favours the emergence of hypertension, when the D allele and the DD and DI genotypes are unfavourable, constituting a specific clinical risk factor for the development of SAH. ${ }^{9}$ Alternatively, another hypothesis suggests that the polymorphism does not contribute to SAH and that it has no effect on the level of BP and homeostasis. ${ }^{10}$

Consequently, the present study aimed to characterize the sampled patients regarding epidemiological parameters for $\mathrm{SAH}$ and to demonstrate the relationship of the I/D polymorphism of the Ace gene and its genotypic variants with regard to BP, in relation to the following classes of patients: obese, non-obese, and those with type 2 diabetes mellitus (T2DM).

\section{Methods}

The study was conducted in the municipality of Pinhão, Paraná, Brazil in three Health Units, over two stages. In the first stage, the collection of anthropometric data (BMI-Body Mass Index and waist circumference) was performed, as well as medications in use, $\mathrm{BP}$ and data from recent routine laboratory tests (total cholesterol, triglycerides and fasting glucose). In the second stage, the collection of peripheral blood was performed for each patient. In total, 112 male and female individuals participated in the study, of which 83 were aged over fifty years and taking three or more medications to control BP. The sample were classified into three groups of hypertensive patients in different classes: non-obese (Group 2: $\mathrm{SAH}+\mathrm{NO}$ ), obese (Group 
3: $\mathrm{SAH}+\mathrm{O}$ ), and obese with T2DM (Group 4: $\mathrm{SAH}+\mathrm{O}+\mathrm{T} 2 \mathrm{DM}$ ). In addition, a group of 29 individuals was sampled and classified as negative control, normotensive (Group 1).

All the participants signed an informed consent according the Ethics Committee on Human Research (COEP, State University of Ponta Grossa; Resolution CNS 196/96 with the research protocol no. 13664/11 and file 47/2012).

The DNA samples were extracted from peripheral blood

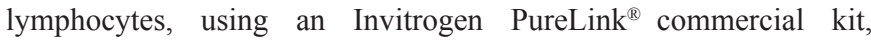
according to the manufacturer's instructions. The genotyping of the I/D polymorphism of the Ace gene for each individual was performed by PCR (polymerase chain reaction), followed by electrophoresis in $1 \%$ agarose gel.

The primers used in this analysis were obtained according to Lindpaintner et $\mathrm{al}^{7}$ and had the following sequences: ACE $1 \mathrm{~F}$ (forward): 5'-GCCCTGCAGGTGTCTGCAGCATGT3' and ACE 1R (reverse): 5'-GGATGGCTCTCCCCGCCTT GTCTC-3'. The PCR reactions were performed in a final volume of $15 \mu \mathrm{L}$, under the following conditions: $1.5 \mu \mathrm{L}$ of $(1 \mathrm{X})$ reaction buffer (containing $200 \mathrm{mM}$ of Tris, $\mathrm{pH} 8.4$ and $500 \mathrm{mM}$ of KCL); $0.25 \mu \mathrm{L}$ of Taq DNA Polymerase $(5 \mathrm{U} / \mu \mathrm{L})$ (Invitrogen $\left.{ }^{\circledR}\right) ; 1 \mu \mathrm{L}$ of $\mathrm{MgCl}_{2}(50 \mathrm{mM}) ; 1 \mu \mathrm{L}$ of dNTP $(2 \mathrm{mM})\left(\right.$ Ludwig Biotec $\left.^{\circledR}\right) ; 0.6 \mu \mathrm{L}$ of foward primer and $0.6 \mu \mathrm{L}$ of reverse primer $(10 \mathrm{mM})\left(\right.$ Ludwig Biotec $\left.^{\circledR}\right)$, and 20ng of genomic DNA obtained from study participants. The polymerization reactions were performed in a thermocycler $\left(\right.$ Biocycler $\left.^{\circledR}\right)$ under the following program: initial denaturation for 5 minutes at $94^{\circ} \mathrm{C} ; 5$ cycles: 1 minute at $94^{\circ} \mathrm{C}, 30$ seconds at $57.5^{\circ} \mathrm{C}, 45$ seconds at $72^{\circ} \mathrm{C}$; followed by 30 cycles of: 1 minute at $94^{\circ} \mathrm{C}, 30$ seconds at $56^{\circ} \mathrm{C}, 45$ seconds at $72^{\circ} \mathrm{C}$, ending with a final extension of 7 minutes at $72^{\circ} \mathrm{C}$. The samples were subjected to electrophoresis in 1.5\% agarose gel stained with GelRed $\left(\right.$ Biotium $\left.^{\circledR}\right)$ to verify the amplification of DNA fragments.

For the analysis of the parameters of population genetics, the TFPGA (Tools for Population Genetic Analyses) ${ }^{11}$ program was used in order to verify the allelic and genotypic frequencies. The HardyWeinberg Equilibrium, the pattern of genetic differentiation between groups with Wright's F-statistics, ${ }^{12}$ and Reynold's distances ${ }^{13}$ were also used. The genotype frequencies were compared between groups using Person's chi-square test, with 5\% significance level, using the Statistica 7.0 (StatSoft, Inc. 2001) program. For the remaining BP data, sedentary or not, smoker or non-smoker, laboratory tests, family history of SAH, BMI and waist circumference, MANOVA multivariate analysis was performed using Wilks, Pillai's, Hotelling and Roy's tests, and a posteriori Tukey's test at 5\% significance, as well as correlation analysis and multiple linear regression $(p<0.05)$, all through the Statistica 7.0 (StatSoft, Inc. 2001) program.

\section{Results}

The epidemiological data from the sampled patients of each group are summarized in Table 1.

\section{Multivariate analysis (MANOVA)}

The MANOVA for the data of waist circumference, total cholesterol, triglycerides, glucose, systolic blood pressure (SBP) and diastolic blood pressure (DBP) did not result in significant differences for the variables, I/D polymorphism, smoking, and family history of SAH, when using Wilks, Pillai's Hotelling and Roy's tests (Table 2 ). Subsequently, Tukey's test, with $95 \%$ confidence $(p<0.05)$, was performed in order to determine possible statistical differences for each categorical variable in relation to the dependent variables. The results are shown in Table 3 .

The analysis between genders only revealed significant differences for total cholesterol, with the highest value assigned to the female sex (Table 3).

An analysis of the different age groups of the population sample indicated significance of data as to the value of triglycerides in the age groups 60-69 and 70-79, and regarding SBP, in the age groups 70-79 and 80-82 (Table 4).

Table I Epidemiological data

\begin{tabular}{|c|c|c|c|c|}
\hline & $\begin{array}{l}\text { Group I } \\
\text { normotensive }\end{array}$ & $\begin{array}{l}\text { Group } 2 \\
\text { SAH+NO }\end{array}$ & $\begin{array}{l}\text { Group } 3 \\
\text { SAH+O }\end{array}$ & $\begin{array}{l}\text { Group } 4 \\
\text { SAH+DM2 }\end{array}$ \\
\hline & n: 29 & $\mathrm{n}: 30$ & n: 24 & n:29 \\
\hline Age & $59.14( \pm 5.92)$ & $63.43( \pm 8.89)$ & $64.17( \pm 9.34)$ & $65.17( \pm 8.81)$ \\
\hline SBP & $118.62( \pm 13.55)$ & $135.3( \pm \mid 5.25)$ & $134.17( \pm \mid 3.81)$ & $139.66( \pm 24.57)$ \\
\hline DBP & $78.45( \pm 8.77)$ & $86.33( \pm 9.99)$ & $84.17( \pm 9.29)$ & $86.55( \pm 12.89)$ \\
\hline BMI & $28.13( \pm 4.75)$ & $26.75( \pm 2.5 \mathrm{I})$ & $34.05( \pm 4.75)$ & $30.56( \pm 5.33)$ \\
\hline WC & $93.14( \pm 12.10)$ & $92( \pm 8.34)$ & $109.50( \pm 13.54)$ & $102.66( \pm 10.10)$ \\
\hline TCT. cholest & $190.45( \pm 48.69)$ & $188.26( \pm 49.93)$ & $186.88( \pm 35.7 \mid)$ & $\mid 48.38( \pm 4|.4|)$ \\
\hline Triglycerides & $14 \mid .55( \pm 74.10)$ & |42.4(士90.90) & $155.58( \pm 53.34)$ & $201.62( \pm 132.73)$ \\
\hline F. Glucose & $90.14( \pm 9.50)$ & $89.23( \pm|2.3|)$ & $90.58( \pm 13.23)$ & $|4| .03( \pm 44.43)$ \\
\hline Sedentary & $58.60 \%$ & $20.00 \%$ & $83.30 \%$ & $63.30 \%$ \\
\hline Smoker & $24.10 \%$ & $23.30 \%$ & $20.80 \%$ & $23.30 \%$ \\
\hline F. His. SAH & $65.50 \%$ & $80.00 \%$ & $79.10 \%$ & $80.00 \%$ \\
\hline
\end{tabular}

SAH, Systemic arterial hypertension; NO, non-obese; O, obese;T2DM, diabetes mellitus type 2; SBP, systolic blood pressure; DBP, diastolic blood pressure; BMI, body mass index; WC, waist circumference; TG, triglycerides; TCT cholest, total cholesterol; F Glucose, fasting glucose, F His. SAH, family history of SAH 
Table 2 Wilks, Pillai's, Roy's and Hotelling's tests to verify the significance of the variables

\begin{tabular}{|c|c|c|c|c|c|c|}
\hline & WC & Total cholesterol & Triglycerides & Fasting Glucose & SBP & DBP \\
\hline Groups (4) & + & + & + & + & + & + \\
\hline Gender & + & + & + & + & + & + \\
\hline Age & + & + & + & + & + & + \\
\hline Sedentary & + & + & + & + & + & + \\
\hline BMI & + & + & + & + & + & + \\
\hline I/D Polymorphism & n.s & n.s & $\mathrm{n} . \mathrm{s}$ & n.s & n.s & n.s \\
\hline Smoker & n.s & n.s & $\mathrm{n} . \mathrm{s}$ & n.s & n.s & n.s \\
\hline Family history of SAH & n.s & n.s & n.s & n.s & n.s & n.s \\
\hline
\end{tabular}

WC, waist circumference, SBP, systolic blood pressure, DBP, diastolic blood pressure, n.s, non-significant value, + , significant value $(<0.05)$

Table 3 Tukey's test for groups, gender and the variables WC, total cholesterol, triglycerides, fasting glucose, SBP and DBP

\begin{tabular}{|c|c|c|c|c|c|c|}
\hline WC & Normotensive & $\mathrm{SAH}+\mathrm{NO}$ & $\mathrm{SAH}+\mathrm{O}$ & SAH+DM2 & $\mathbf{F}$ & $\mathbf{M}$ \\
\hline Normotensive & & 0.979006 & 0.000140 & 0.007635 & & \\
\hline SAH and non-obese & 0.979006 & & 0.000138 & 0.001990 & & \\
\hline SAH and obese & 0.000140 & 0.000138 & & 0.118112 & & \\
\hline Diabetes and SAH & 0.007635 & 0.001990 & 0.118112 & & & \\
\hline $\mathrm{F}$ & & & & & & 0.249780 \\
\hline M & & & & & 0.249780 & \\
\hline \multicolumn{7}{|l|}{ Total cholesterol } \\
\hline Normotensive & & 0.997714 & 0.991547 & 0.002901 & & \\
\hline SAH and non-obese & 0.997714 & & 0.999541 & 0.004778 & & \\
\hline SAH and obese & 0.991547 & 0.999541 & & 0.012191 & & \\
\hline Diabetes and SAH & 0.002901 & 0.004778 & 0.012191 & & & \\
\hline $\mathrm{F}$ & & & & & & 0.002493 \\
\hline M & & & & & 0.002493 & \\
\hline \multicolumn{7}{|l|}{ Triglycerides } \\
\hline Normotensive & & 0.999980 & 0.610200 & 0.124889 & & \\
\hline SAH and non-obese & 0.999980 & & 0.580077 & 0.109875 & & \\
\hline $\mathrm{SAH}$ and obese & 0.610200 & 0.580077 & & 0.814001 & & \\
\hline Diabetes and SAH & 0.124889 & 0.109875 & 0.814001 & & & \\
\hline $\mathrm{F}$ & & & & & & 0.584581 \\
\hline M & & & & & 0.584581 & \\
\hline \multicolumn{7}{|l|}{ Fasting glucose } \\
\hline Normotensive & & 0.993552 & 1.000000 & 0.000138 & & \\
\hline SAH and non-obese & 0.993552 & & 0.994954 & 0.000138 & & \\
\hline SAH and obese & 1.000000 & 0.994954 & & 0.000138 & & \\
\hline Diabetes and SAH & 0.000138 & 0.000138 & 0.000138 & & & \\
\hline $\mathrm{F}$ & & & & & & 0.732201 \\
\hline M & & & & & 0.732201 & \\
\hline \multicolumn{7}{|l|}{ SBP } \\
\hline Normotensive & & 0.000974 & 0.003893 & 0.000197 & & \\
\hline SAH and non-obese & 0.000974 & & 0.996745 & 0.891478 & & \\
\hline SAH and obese & 0.003893 & 0.996745 & & 0.813685 & & \\
\hline Diabetes and SAH & 0.000197 & 0.891478 & 0.813685 & & & \\
\hline $\mathrm{F}$ & & & & & & 0.564972 \\
\hline M & & & & & 0.564972 & \\
\hline \multicolumn{7}{|l|}{ DBP } \\
\hline Normotensive & & 0.019232 & 0.177632 & 0.016447 & & \\
\hline SAH and non-obese & 0.019232 & & 0.872882 & 0.999838 & & \\
\hline $\mathrm{SAH}$ and obese & 0.177632 & 0.872882 & & 0.840821 & & \\
\hline Diabetes and SAH & 0.016447 & 0.999838 & 0.840821 & & & \\
\hline $\mathrm{F}$ & & & & & & 0.653770 \\
\hline M & & & & & 0.653770 & \\
\hline
\end{tabular}

$\mathrm{SAH}$, Systemic arterial hypertension; NO, non-obese; O, obese; DM2, diabetes mellitus type 2. The values in bold indicate significant differences 
Table 4 Tukey's test for age, BMI and the variables,WC, total cholesterol, triglycerides, fasting glucose, SBP and DBP

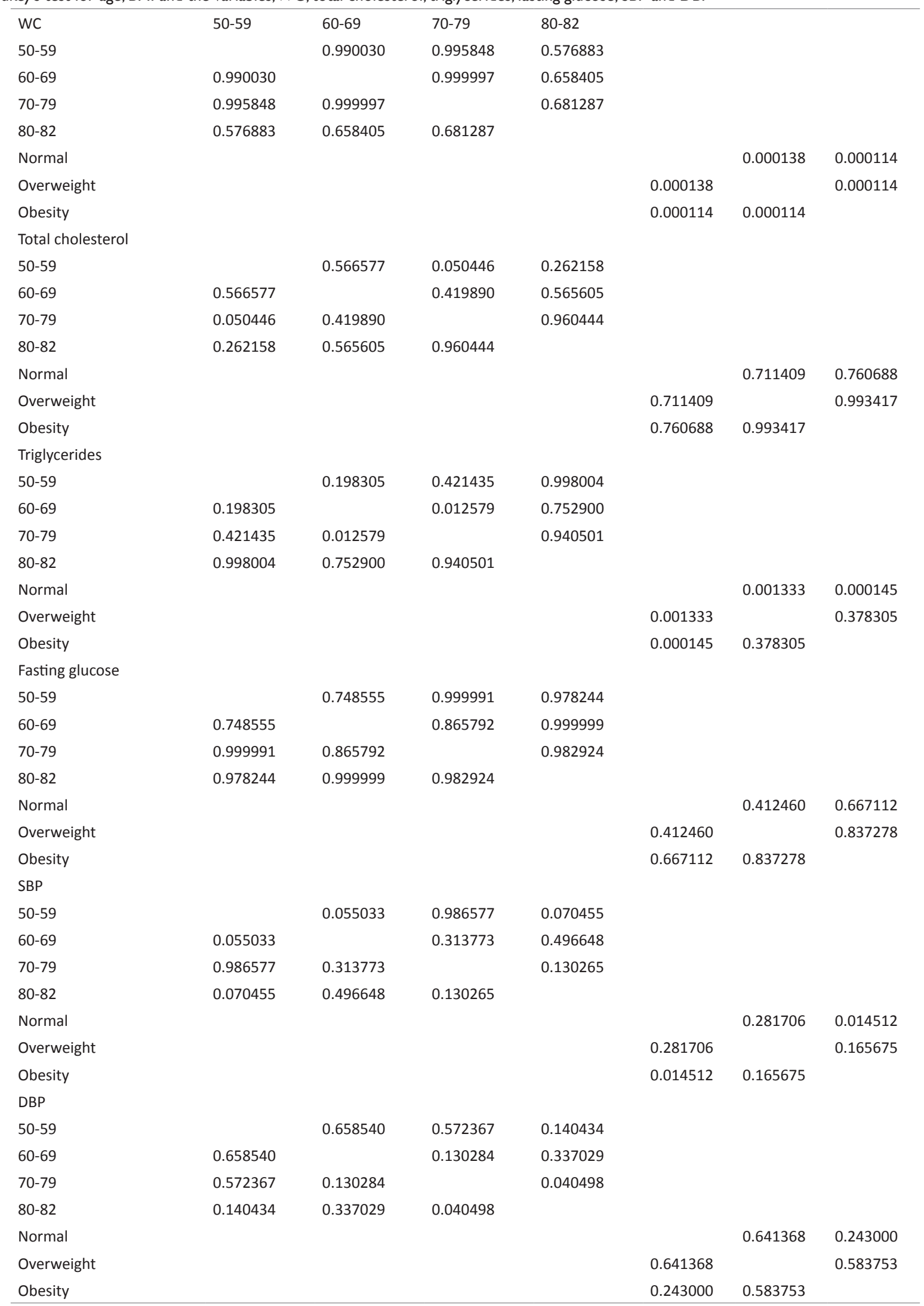

Values in bold indicate significant differences.

Citation: Umburanas RC, Estabile PC, Mateus RC, et al.ACE Gene I/D polymorphism and systemic arterial hypertension in different classes of hypertensive individuals. MOJ Biol Med. 2019;4(I):22-28. DOI: 10.15406/mojbm.2019.04.00108 
Regarding BMI, a significant relationship was found between waist circumference and all classes of BMI. Triglyceride values were significant between the normal and overweight groups, and the normal and the obese groups, while in relation to SBP there was difference between the normal and obese individuals, with the highest values attributed to obesity (Table 4).

Regarding sedentarism, there was a significant increase in waist circumference for the individuals who did not practice any physical activity.

Linear regression showed a significant association between SBP and DBP. The $\mathrm{R}^{2}$ value of the linear regression model between DBP and SBP was $57.52 \%$. The graph in Table 3 shows that the higher the DBP, the higher the SBP, with a $57.52 \%$ correlation coefficient $\left(\mathrm{R}^{2}\right)$.

\section{I/D polymorphism of the Ace gene}

The I/D polymorphism for the Ace gene was efficiently amplified, as described by Lindpaintner et al. ${ }^{7}$ and its genotypes were identified. The genotypes were tabulated into groups, as shown in Table 5.

Taking into consideration the 112 individuals, the allele/gene and genotypic frequencies for the I/D polymorphism of the $\mathrm{ACE}$ gene can be seen in Table 5; all of the genotype frequencies were outside the Hardy-Weinberg equilibrium (HWE) $(\mathrm{p}<0.05)$.

Table 5 Genotypic, gender classification, gene frequencies (D, I) and genotypes (DD, ID, II) for the I/D polymorphism of the ACE gene and $P$ value in all of the analyzed individuals and by groups. Group I, normotensive; Group 2, hypertensive (SAH) and non-obese; Group 3, hypertensive and obese; and Group 4, hypertensive and diabetes mellitus type 2

\begin{tabular}{|c|c|c|c|c|c|}
\hline Alelle/Genotype & Total & $\begin{array}{l}\text { Group } 1 \\
\text { Normotensive }\end{array}$ & $\begin{array}{l}\text { Group } 2 \mathrm{SAH} \text { and } \\
\text { non-obese }\end{array}$ & $\begin{array}{l}\text { Group } 3 \\
\text { SAH and obese }\end{array}$ & $\begin{array}{l}\text { Group } 4 \\
\text { SAH and DM2 }\end{array}$ \\
\hline $\mathrm{n}$ & 112 & 29 & 30 & 24 & 29 \\
\hline DD & & 8 & 7 & 7 & 5 \\
\hline ID & & 17 & 21 & 12 & 18 \\
\hline II & & 4 & 2 & 2 & 6 \\
\hline F & & 15 & 16 & 15 & 15 \\
\hline M & & 14 & 14 & 9 & 14 \\
\hline Freq D & 0.5446 & 0.5690 & 0.5833 & 0.5417 & 0.4828 \\
\hline Freq I & 0.4554 & 0.4310 & 0.4167 & 0.4583 & 0.5172 \\
\hline Freq DD & 0.2411 & 0.2759 & 0.2333 & 0.2917 & 0.1724 \\
\hline Freq ID & 0.6071 & 0.5862 & 0.7000 & 0.5000 & 0.6207 \\
\hline Freq II & 0.1518 & 0.1379 & 0.0667 & 0.2083 & 0.2069 \\
\hline P value & 0.0245 & 0.4442 & 0.0276 & 1.0000 & 0.2771 \\
\hline
\end{tabular}

Genotypes: deletion/deletion DD, insertion/deletion, ID, insertion/insertion II; M, male, F, female; $n$, number of individuals per group

The allele and genotype frequencies were obtained by taking into consideration the grouping of the population into four classes (groups), as shown in Table 5. The classes that were shown to be within the HWE were groups 1, 3 and 4, while group 2 was outside of HWE. The comparison of frequencies between the groups was assessed using Pearson's chi-square test, which determined the significance of the differences found between the two groups, and this showed that there was no significant difference between them (chi-square $=4.4339, \mathrm{p}=$ $0.6174)$.

The analysis of genetic differentiation ( $F$ statistic) was low (Fst $<0.05)$. In order to measure the genetic distance between the population pairs, Reynold's et al. ${ }^{8}$ distance was used. The greatest distances were found between the SAH and non-obese group, and between the SAH and T2DM group (0.0032). The lowest distance was between the normotensive group, and the $\mathrm{SAH}$ and obese group $(-0.0177)$.

\section{Discussion}

The I/D polymorphism of the ACE gene in the intron 16 region is attributed to a phenomenon known as linkage disequilibrium, ${ }^{14}$ which describes the degree of non-random association between two alleles at two different loci of the same chromosome. ${ }^{15}$ This polymorphism has been associated with $\mathrm{SAH},{ }^{9}$ atherosclerosis ${ }^{16}$ and coronary heart disease, such as acute myocardial infarction. ${ }^{6}$ The $\mathrm{D}$ allele has been attributed with being responsible for an increase in vascular vasoconstriction, ${ }^{16}$ due to increased ACE levels in the plasma and tissues of individuals with the D allele. ${ }^{16,17}$ However, some studies have not found this association with the occurrence of coronary artery disease, ${ }^{7}$ brain injury, ${ }^{18}$ deep venous thrombosis and thromboembolism ${ }^{19}$ and $\mathrm{SAH},{ }^{5}$ leaving the biological significance of the I/D polymorphism of the ACE gene remaining an open question.

The present study did not reveal the relationship between the I/D polymorphism of the ACE gene and SAH because the genotypic differences between the four sampled groups was not significant. The family history of SAH was also not found to be associated, and these were the environmental factors that most contributed to the development of SAH in the analyzed sample.

Obesity and waist circumference were prevalent factors that contributed to the SAH profile in this study, with increased values in the SAH and obese group, and the SAH and T2DM group, which were related to increased values of BMI and sedentarism. Total cholesterol was prevalent in the SAH and T2DM group, and it was higher for females. Increased values of triglycerides were found for those aged 60-69 and in obese individuals. Increased SBP values were most evident in the three groups with $\mathrm{SAH}$ and in individuals with obesity, and those individuals with DBP aged over 80 , as well as the SAH and 
non-obese group, and the SAH and T2DM group. These data support the hypothesis that individuals with $\mathrm{SAH}$ are at increased risk of developing T2DM and dyslipidemia. ${ }^{20}$

The close relationship between the increase in SBP and DBP reinforces the hypothesis of the elevated levels of hypertension in most of the individuals. Although increased DBP has been associated with the DD genotype ${ }^{21}$ no correlation was observed in the present study between the ACE genotypes and SBP or DBP. Our data only indicated the associations between DBP and advanced age (over 80 years old), in the SAH and non-obese group, and the SAH andT2DM group, but not with respect to I/D polymorphism.

However, we do not rule out the possibility that genetic factors are associated with SAH. Hereditary factors, combined with environmental risk factors, are important in the onset of SAH. Montgomery et al. ${ }^{22}$ evaluated the relationship between I/D polymorphism of ACE and the growth of the left ventricle (LV) only in individuals with II and DD homozygous genotypes, undergoing 10 weeks of physical activity. Those individuals with the DD genotype had a greater hypertrophic response than those with the II genotype.

From an evolutionary standpoint, in the hypertensive and normotensive population that was studied, the genotypic frequencies were outside the HWE, but when they were considered in groups, such as subpopulation, only group 2 (SAH and non-obese) was outside the HWE. According to Beiguelman, ${ }^{23}$ the HWE is only maintained in a population if evolutionary factors such as mutation, natural selection, genetic drift, gene flow of migrant populations, and endogamy are not present. As the heterozygous genotype frequency for the SAH and non-obese group was 0.700 , this effect can be attributed to a selection in favor of the heterozygote, or random drift, due to the small population size. No genetic structure (Fst) was observed in the sample, thus there was no association of the genotype classes with the four groups.

In a study of 210 individuals, conducted in Brazil by Inácio et al., ${ }^{24}$ the allele frequency for the ACE gene was 0.39 and 0.61 , for the I allele and the $\mathrm{D}$ allele, respectively, and the genotype frequencies were II: 0.20 ; ID: 0.43 ; and DD: 0.37 . When conducted in southern Brazil, this was 0.35 and 0.65 for the I allele and D allele, respectively and the genotype frequencies were II: 0.22 ID; 0.24 and DD: 0.54 , which differed from the Brazilian population as a whole, with increased DD homozygous genotype and decreased heterozygote. The findings were attributed to the different ethnic composition of the region and the small sample might have favoured random drift. The population investigated in the present study was also from southern Brazil, consisting of 112 individuals who obtained values of 0.4554 for the I allele and 0.5446 for the D allele. The values for the DD, ID and II genotypes were $0.2411,0.6071$ and 0.1518 , respectively. These results differ from those obtained by Inácio et al. ${ }^{24}$ for southern Brazil, with a greater frequency of the heterozygote genotype, and not for the DD homozygote, as had been expected. This result is even more surprising because the present study deliberately included patients screened for SAH and its comorbidities.

\section{Conclusion}

In conclusion, the analysis of the association of the $\mathrm{I} / \mathrm{D}$ polymorphism of the ACE gene with $\mathrm{SAH}$, taking into consideration different classes of hypertensive and normotensive individuals, did not result in statistically significant associations, leading to the conclusion that environmental factors are more prevalent, even in relation to family history, in the determination of SAH in the population studied here.

\section{Acknowledgments}

None.

\section{Conflicts of interest}

Author declares no conflicts of interest.

\section{References}

1. Brazilian Society of Cardiology/Brazilian Society of Hypertension / Brazilian Society of Nephrology. VI Brazilian Guidelines on Hypertension. Arq Bras Cardiol. 2010;95(1 Supl1):1-51.

2. Young JH. Evolutions of blood pressure regulation in humans. Curr Hypertens Rep. 2007;9(1):13-18.

3. Guyton AC, Hall JE. Treaty of Medical Physiology. 12th edn. Rio de Janeiro: Elsevier; 2011.

4. Lee MA, Bohm M, Paul M, et al. Tissue renin-angiotensin systems:their role in cardiovascular disease. Circulation. 1993;87(Suppl 5):7-13.

5. Jeunemaitre X, Lifton PR, Hunt SC, et al. Absence of linkage between angiotensin enzyme locus essential hypertension. Nat Genet. 1992;1(1):72-75

6. Cambien F, Poirier O, Lecerf L, et al. Deletion polymorphism in the gene for angiotensin-converting enzyme is a potent risk factor for myocardial infarction. Nature. 1992;359(6396):641-644.

7. Lindpaintner K, Pfeffer MA, Kreutz R, et al. A prospective evaluation of an angiotensin-converting-enzyme gene polymorphism and the risk of ischemic heart disease. N Engl J Med. 1995;332(11):706-711.

8. Rigat B, Hubert C, Alhenc-Gelas F, et al. An insertion-deletion polimorphism in the angiotensin-I converting enzyme gene accounting for half of the variance of serum enzyme levels. $J$ Clin Invest. 1990;86(4):1343-1346

9. Freitas SRS, Cabello PH, Moura-Neto RS, et al. Combined analysis of genetic and environmental factors on essential hypertension in a Brazilian Rural population in the Amazon region. Arq Bras Cardiol. 2007;88(4):447-451.

10. Mondorf UF, Russ A, Wiesemann A, et al. Contribution of Angiotensin I-Converting Enzyme Gene Polymorphism and Angiotensinogen Gene Polymorphism to Blood Pressure Regulation in Essential Hypertension. Am J Hypertens. 1998;11(2):174-183.

11. Miller MP. Tools for Population Genetic Analyses (TFPGA), ver 1.3. A windows program for the analysis of allozyme and molecular population genetic data. 1997.

12. Wright S. Evolution in Mendelian population. Genetics. 1931;16(2):97159.

13. Reynolds J, Weir BS, Cockerham CC. Estimation of the Coancestry Coefficient:Basis for a Short-Term Genetic Distance. Genetics. 1983;105(3):767-779.

14. Keavney B. Genetic epidemiological studies of coronary heart disease. Int J Epidemiol. 2002;31(4):730-736.

15. Pasternak JJ. Introduction to Human Molecular Genetics: Mechanisms of Hereditary Diseases. $2^{\text {nd }}$ edn. Rio de Janeiro: Guanabara Koogan; 2007.

16. Prasad A, Narayanan S, Waclawiw MA, et al. The Insertion/Deletion Polymorphism of the Angiotensin-Converting Enzyme Gene 
Determines Coronary Vascular Tone and Nitric Oxide Activity. $J$ Am Coll Cardiol. 2000;36(5):1579-1586.

17. Fonseca FAH, Izar MCO. Polimorfismos em Genes relacionados ao Sistema Renina-Angiotensina-Aldosterona, associação com a doença arterial coronariana e suas características anatômicas. Arq Bras Cardiol. 2004;83(5):371-372.

18. Dikmen M, Günes HV, Degirmenci I, et al. Are the angiotensinconverting enzyme gene and activity risk factors for stroke? Arq Neuropsiquiatr. 2006;64(2A):211-216.

19. Munhoz TP, Scheibe RN, Schmitt VM. Angiotensin converting enzyme (ACE) DD genotype:relationship with venous thrombosis. Rev Bras Hematol Hemoter. 2005;27(2):87-90.

20. Carneiro G, Faria AN, Ribeiro-Filho FF, et al. Influence of body fat distribution on the prevalence of hypertension and other cardiovascular risk factors in obese individuals. Rev Assoc Med Bras. 2003;49(3):306311 .

21. Jiménez PM, Conde C, Casanegra A, et al. Association of ACE genotype and predominantly diastolic hypertension:a preliminary study. JRAAS. 2007;8(1):42-44.

22. Montgomery H, Brull D, Humphries SE. Analysis of gene-environment interactions by "stressing-the-genotype" studies:the angiotensin converting enzyme and exercise-induced left ventricular hypertrophy as an example. Italian Heart J. 2002;3(1):10-14.

23. Beiguelman B. Genetics of human populations. Ribeirão Preto: SBG; 2008 .

24. Inácio J, Goulart-Filho LR, Vieira GS. F Genotypic and allelic frequencies of the ACE I/D polymorphism gene in the population. Biosci J. 2004;20(1):47-51. 